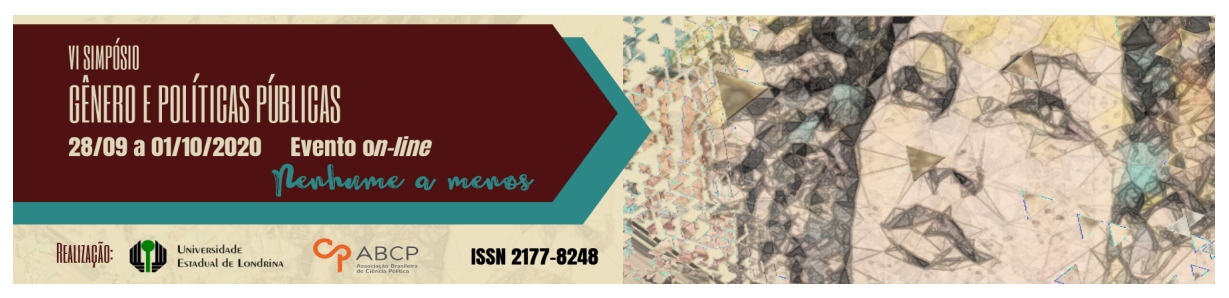

\title{
Relato de experiência do projeto Rizoma
}

\author{
Alana Morais Vanzela ${ }^{1}$; Liliane Wielewski Pobbe Mainardes²
}

\section{Resumo}

Este trabalho é o resultado da ação intersetorial das Políticas Públicas de Educação e Assistência Social de um município de pequeno porte I do Estado do Paraná, que detectaram uma demanda crescente de problemas de saúde correlacionadas a questões de gênero, para tanto, as profissionais do CREAS propuseram a implantação de um projeto voltado ao público da instituição Escola/Casa Familiar Rural, com o objetivo de resgatar a autoestima e desnaturalizar as diversas expressões da violência de gênero. O Projeto contou com nove encontros, que buscou dialogar sobre temas como: emoções e sua forma expressão no cotidiano, mediação de conflitos; cultura e a sua relação com os papéis sociais de gênero; diversidade, sororidade e projetos de vida. A partir desse projeto percebeu-se que houve uma significativa diminuição dos conflitos interpessoais entre as adolescentes e consequentemente dos encaminhamentos para a Unidade Básica de Saúde.

Palavras-chave: gênero; mulher rural; intersetorialidade.

\section{Experience report of the Rizoma project}

\section{Abstract}

This work is the result of the intersectoral action of the Public Policies of Education and Social Assistance of a small municipality I of the State of Paraná, which detected an increasing demand for health problems correlated

\footnotetext{
1 Mestranda em Ciências Sociais - UEM atua como Assistente Social no Centro de Referência Especializado de Assistência Social, email: alanavanzela@gmail.com.

2 Mestre em Psicologia - UEL atua como psicóloga no Centro de Referência Especializado de Assistência Social, email: li_pobbe@hotmail.com.
}

GT 08 - Gênero, Educação e Escola 
with gender issues, so creas professionals proposed the implementation of a project aimed at the public of the institution Escola/Casa Familiar Rural, with the objective of rescuing self-esteem and denaturalizing the various expressions of gender violence. The Project had nine meetings, which sought to dialogue on topics such as: emotions and their expression form in daily life, conflict mediation; culture and its relationship with gender social roles; diversity, sorority and life projects. From this project, it was noticed that there was a significant decrease in interpersonal conflicts between adolescents and consequently referrals to the Basic Health Unit.

Keywords: gender; rural roman; intersectoriality.

\section{Introdução}

Este trabalho é o resultado da ação intersetorial das Políticas Públicas de Educação e Assistência Social de um município de pequeno porte I do Estado do Paraná, que detectaram uma demanda crescente de problemas de saúde correlacionadas a questões de gênero, para tanto, as profissionais do CREAS fizeram a implantação de um projeto voltado ao público da instituição Escola/Casa Familiar Rural, com o objetivo de resgatar a autoestima e desnaturalizar as diversas expressões da violência de gênero. Destaca-se que esta instituição adota regime curricular de alternância e que o Projeto foi implantado no final do segundo semestre do ano de 2019.

O Projeto contou com nove encontros, no primeiro encontro foi realizado o levantamento das demandas do público e estabelecimento de compromissos; no segundo encontro foram realizadas atividades que visavam refletir sobre as emoções e a forma como são expressas no cotidiano; no terceiro e quarto encontros buscou-se refletir o funcionamento geral das emoções para na sequência discutir-se como a cultura sedimenta funções e formas de expressão dos papéis sociais de gênero; no quinto encontro foi realizada reflexão sobre diversidade, diferença, desigualdade; no sexto encontro discutiu-se o conceito de sororidade e meios de conciliação de conflitos; no sétimo encontro foi retomada a discussão de autoconhecimento e reflexão sobre projetos de vida; no oitavo encontro foi realizado o aprofundamento da 
discussão sobre papéis sociais de gênero e introdução do conceito de patriarcado; no nono encontro foi realizada dinâmica de grupo em que as adolescentes foram levadas a expressar a forma como passaram a se (re)conhecer, para na sequência, realizar-se a avaliação conjunta do projeto.

A partir desse projeto percebeu-se que houve uma significativa diminuição dos conflitos interpessoais entre as adolescentes e consequentemente dos encaminhamentos para a Unidade Básica de Saúde.

\section{Plantando uma Semente: O surgimento do projeto.}

O Projeto Rizoma foi idealizado pelas profissionais de Psicologia e Serviço Social lotadas no Centro de Referência Especializado de Assistência Social - CREAS, e pode ser compreendido como uma resposta de uma demanda intersetorial entre as Políticas de Assistência Social e Educação.

Os encontros do projeto foram pensados para se materializarem como um espaço de apoio, orientação e acompanhamento das adolescentes, encaminhadas pela coordenação da Escola/Casa Familiar Rural, e que tinham demandas relacionadas: ao fortalecimento dos vínculos comunitários; de conflitos vinculadas a fase do ciclo geracional, riscos pessoal e social atrelado a expressões da violência de gênero.

Destaca-se que a intervenção da unidade de atendimento CREAS foi desenvolvida de forma concomitante com a intervenção institucional da equipe pedagógica da Escola/Casa Familiar Rural, portanto não se trata de uma substituição do espaço de intervenção escolar, mas sim, da potencialização de um trabalho desenvolvido em rede.

Antes de prosseguir com o debate, devemos situar o leitor que a demanda apresentada pela coordenação da Escola/Casa Familiar 
Rural dialoga com o papel que deve ser desenvolvido pela unidade de atendimento CREAS. Desta forma, o Projeto Rizoma pode ser compreendido como uma estratégia de atendimento em grupo, que se vincula ao Serviço de Proteção e Atendimento Especializado a Famílias e Indivíduos (PAEFI), que tem como objetivos:

- Contribuir para o fortalecimento da família no desempenho de sua função protetiva;

- Processar a inclusão das famílias no sistema de proteção social e nos serviços públicos, conforme necessidades;

- Contribuir para restaurar e preservar a integridade e as condições de autonomia dos usuários;

- Contribuir para romper com padrões violadores de direitos no interior da família;

- Contribuir para a reparação de danos e da incidência de violação de direitos;

- Prevenir a reincidência de violações de direitos (BRASIL, TIPIFICAÇÃO DOS SERVIÇOS SOCIOASSISTENCIAIS, 2014, p. 29).

E que visa instituir os seguintes impactos na vida dos indivíduos e de suas famílias:

- Redução das violações dos direitos socioassistenciais, seus agravamentos ou reincidência;

- Orientação e proteção social a Famílias e indivíduos;

- Acesso a serviços socioassistenciais e das políticas públicas setoriais;

- Identificação de situações de violação de direitos socioassistenciais;

- Melhoria da qualidade de vida das famílias (BRASIL, TIPIFICAÇÃO DOS SERVIÇOS SOCIOASSISTENCIAIS, 2014, p. 31). 
O projeto buscou identificar, desnaturalizar e romper com padrões violadores de direitos associados aos papéis sociais de gênero que eram (re)cobrados no interior da família e comunidade. Inclusive, cabe sinalizar que o nome dado ao Projeto, não foi escolhido de forma aleatória, ele tem a intencionalidade de fazer referência ao local de fala das adolescentes, pois um requisito para o ingresso na Escola/Casa Familiar Rural é ter vinculação ao espaço rural. Sabe-se que o termo "Rizoma" na biologia pode ser caracterizado como um caule subterrâneo, que gera ramos, todavia, esse termo, também possui sentido na teoria feminista, compreendido como uma crítica ao termo "onda":

A derivação metafórica da palavra onda contém, sim, significados de tempo curto que, de fato, substantivam manifestações observadas como "novas" a cada tempo, em eventos sucessivos na história das mulheres e dos feminismos. Diferenciados por conjunturas, os feminismos, assim, são vistos, em geral, como irrupções em que, de repente, não mais que de repente, mulheres diversas se juntam, mostram-se "irmanadas" na agitação de "causas" ou motivações políticas que se avolumam e que avançam como onda. Esta, depois de atingir um ponto alto, desce, invadindo os mais variados territórios, em diversos tempos; em seguida, tudo parece dissipar-se. Diria que um maior rigor na produção do conhecimento dessas "causas" / motivações depende, sim, de pesquisa de fontes, mas sob uma leitura orientada por conceitos que admitam esses movimentos conjunturais como partes de um vasto tecido social, em grande medida, submersas, vindas de diferentes tempos históricos, trançadas entre si e que avançam em infinitas combinações de "ramificações", continuadas ou não, sinalizando movimentos e transformações de visões de mundo"(COSTA, 2009, pp. 3-4).

Desta forma, o debate proposto para ser desenvolvido no desenrolar do projeto apontava para a essas ramificações históricas, mas também, para as possibilidades de transformações do presente e 
do futuro delas, através das projeções que elas poderiam (re)descobrir de forma individual, mas também em grupo, e que para isso elas poderiam contar com o auxílio dos profissionais da Política de Educação, Assistência Social e Saúde.

\section{Germinação: O Desenvolvimento dos Encontros}

O Projeto foi iniciado no fim do primeiro semestre do ano de 2019, com 9 adolescentes do gênero feminino, que estavam matriculadas na Escola/Casa Familiar Rural, na época elas tinham idades entre 15 a 17 anos. Os encontros do Projeto eram realizados na sala de reuniões do Centro de Referência de Assistência Social (CRAS), devido à facilidade de acesso, uma vez que as instituições são próximas. A periodicidade dos encontros foi em sua maioria quinzenal ${ }^{3}$, destaca-se que a Escola/Casa Familiar Rural adota regime curricular de alternância, e que por isso, o projeto também seguiu esse regime de atividades, cada encontro tinha duração de aproximadamente 60 minutos. Os encontros foram desenvolvidos no formato de rodas de conversa, que eram combinadas a dinâmicas de grupo e/ou exposição de conteúdo, sem perder de vista, a sua finalidade de apresentar as vivências, fazer a troca de informações, fortalecer o grupo e orientar a respeito do conteúdo manifesto (e percebido) pelas profissionais.

O primeiro encontro aconteceu no mês de junho, e foi idealizado como uma forma de aproximação inicial entre as adolescentes e a equipe técnica, no qual foi realizado um novo levantamento das demandas a partir do olhar das adolescentes, uma vez que já tínhamos um levantamento prévio que havia sido apresentado pela equipe pedagógica da Escola/Casa Familiar Rural. $\mathrm{Na}$ sequência foram estabelecidos os compromissos com o grupo,

${ }_{3}^{3}$ Deve-se fazer uma ressalva, a respeito da periodicidade dos encontros, pois alguns deles, tiveram que ser remanejados a pedido da Escola/Casa Familiar Rural devido a atividades de campo, cita-se o exemplo de algumas visitas técnicas a propriedades rurais. Mas em geral, os encontros eram quinzenais. 
como por exemplo: dia da semana, horário e tempo de duração dos encontros quinzenais; respeito entre as participantes do grupo durante os encontros e manutenção do sigilo em relação às falas das colegas durante os encontros.

O segundo encontro foi realizado no mês de julho e foram propostas atividades que visavam refletir sobre as emoções e a forma como são expressas no cotidiano. Para isso, a atividade foi iniciada com a apresentação de um bicho de pelúcia que foi repassado para cada participante do grupo, momento no qual, a participante que estivesse com o bicho de pelúcia em suas mãos deveria externalizar comportamentos de carinho para com ele. Terminado esse primeiro momento, os mesmos comportamentos de carinho deveriam ser apresentados para com a colega da direita. Em seguida, foi realizada uma roda de conversa em que a discussão guiou-se pelas questões: "Será que a gente sempre consegue expressar (colocar para fora) nossos sentimentos da forma como sentimos?"; "E quando colocamos para fora, será que o fazemos de forma adequada?"; "O que são emoções?"; "De que forma se expressam?"; "Podemos controlar nossas emoções?" e "Existem formas mais adequadas de expressão das emoções e sentimentos?"

O terceiro e o quarto encontro, foram realizados nos meses de julho e agosto, buscou-se favorecer o autoconhecimento refletindo sobre o funcionamento geral das emoções humanas para na sequência discutir-se como a cultura sedimenta funções e formas de expressão dos papéis sociais de gênero. Nesses dois encontros fez-se uma discussão com apresentação de slides sobre o funcionamento geral das emoções humanas. Discutiu-se sobre como sentimos a nível fisiológico, como se comporta o organismo frente às emoções e sentimentos vivenciados.

O quinto foi realizado no mês setembro, momento em que fizemos uma dinâmica sobre a diferenças de opiniões das adolescentes que formam o grupo. Para o cumprimento dessa atividade foi tracejada uma linha no meio da sala de reunião, na medida em que 
eram lidas algumas perguntas aleatórias, como "quem gosta mais de azul, fique a direita ou quem gosta mais de vermelho, fique a esquerda", "quem gosta mais de frio fique a direita, quem gosta mais de calor fique a esquerda", "quem gosta mais de doce, fique a direita quem gosta mais de salgado fique a esquerda", conforme o comando e preferência, as adolescentes deveriam se posicionar do lado direito ou esquerdo da linha, de acordo com o seu gosto. O curioso, foi que algumas delas, inclusive as que eram melhores amigas, disseram se surpreender com a resposta da outra. Ao fim das perguntas nos sentamos para discutir as percepções que elas tiveram, elas apresentaram contribuições bem significativas, que foram utilizadas pela equipe técnica como forma de discutir sobre as diferença enquanto parte das relações humanas, e que essa característica social não precisa se transformar em um motivo de uma desigualdade, ou em uma justificativa para uma forma de violência/rivalidade, sendo necessário o exercício da empatia e do respeito as alteridades.

O sexto encontro, foi realizado no mês de setembro, momento em que discutimos sobre as pautas de alguns movimentos feministas, fazendo uma rápida análise sobre as conquistas dos direitos: ao voto, ao corpo, a igualdade de direitos e deveres segundo a constituição federal, sobre pautas identitários, entre outras conquistas.

Neste encontro, o grupo relacionou e explorou diversos conhecimentos que elas já tinham sobre os movimentos feministas, ao mesmo tempo em que conseguiram discutir sobre a ampliação das possibilidades de intervenção e conquistadas obtidas ao longo da história, inclusive, acabaram por surpreender a equipe técnica ao prestar uma análise crítica sobre os desafios que ainda se apresentam para elas no cotidiano. As adolescentes apresentaram exemplos sobre as diversas formas de manifestação da desigualdade de gênero, aproveitaram para citar algumas formas manifestas através da: subrepresentação feminina na política; a projeção e preconceito que algumas delas vivenciaram em âmbito familiar ao fazerem a escolha de ingresso na Escola/Casa Familiar Rural; os desafios relacionados a 
frustração das expectativas de amigos e familiares que relacionavam o gênero feminino ao desempenho de papéis vinculados a economia doméstica, enquanto os desejos e planos delas se vinculam ao sonho de atuação no plantio/técnicas de manejo e/ou lida com os animais, o assédio que permeia um simples trajeto à um estabelecimento comercial ou passeio noturno, entre outros assuntos.

No sétimo encontro, fizemos um apanhado sobre a discussão desenvolvida no sexto encontro, que tinha maior ênfase de análise das expressões da violência e desigualdade de gênero no espaço público. Para então aprofundarmos a análise sobre essas expressões no âmbito privado, utilizamos como recurso metodológico o curta metragem: “Acorda, Raimundo... Acorda!" (1990), que tem duração de 22 minutos. A utilização da linguagem cinematográfica, foi empregada com o objetivo de facilitar e tornar mais leve o diálogo sobre temas como: violência sexual e violência intrafamiliar, que são assuntos mais difíceis de serem explorados, compreendemos que o recurso da representações cinematográfica favorece a possibilidade de desenvolvimento de um relato livre e com a exposição de um ponto de vista, o que talvez pudesse ser constrangido, caso elas tivessem que produzir um relato a partir de uma experiência demarcada como pessoal.

Ao longo do encontro, algumas adolescentes conseguiram estabelecer alguns paralelos entre os assuntos tratados no quinto e sexto encontro, com suas vivências pessoais e/ou com a de algum amigo/familiar. A equipe técnica também procurou rememorar os combinados do grupo, sobre a importância de manter o sigilo sobre os assuntos que são tratados no grupo, por fim, fechamos o debate com a discussão sobre o conceito de sororidade, estratégias e meios de denúncia dos diversos tipos de violência, diferença entre violência intrafamiliar e conflitos intergeracionais.

O oitavo encontro foi realizado no mês de outubro, momento em que foi retomada a discussão de autoconhecimento, buscamos provocar uma reflexão sobre projetos de vida, foi solicitado que a 
coordenadora da Escola/Casa Familiar Rural entregasse e instruísse as adolescentes sobre o preenchimento de uma folha de papel, que foi entregue no começo da semana, nesta folha de papel haviam duas linhas traçadas, que formavam quatro campos, uma espécie de "Curtigrama". Cada um dos campos vinha acompanhado de um título, um deles dizia: "Gosto e Faço", o outro "Gosto e Não Faço", e os outros dois "Não Gosto e Faço" e "Não Gosto e Não Faço", sendo necessário que cada adolescentes respondesse individualmente, sendo necessário manter segredo sobre a sua atividade.

Neste encontro, foi solicitado para que quem se sentisse confortável em apresentar o seu relato o fizesse, fomos discutindo em blocos, algumas apresentações foram feitas de forma emocionada, e não sendo rara a devolutiva de que elas nunca tinham sido inqueridas sobre aqueles assuntos, e que essa era a primeira oportunidade que elas tiveram de refletir sobre alguns temas. Aproveitamos para discutir sobre os planos de vida em: curto, médio e longo prazo.

O nono encontro foi realizado no mês dezembro, e foi realizado a partir de uma dinâmica de grupo, em que as adolescentes foram levadas a expressar a forma como passaram a se (re)conhecer, para na sequência, realizar-se a avaliação conjunta do projeto.

\section{Novas Sementes: Os resultados parciais do Projeto}

A coordenação da Escola/Casa Familiar Rural sinalizou que o projeto contribuiu para diminuir os conflitos interpessoais entre as adolescentes, e consequentemente dos encaminhamentos para a Unidade Básica de Saúde.

A equipe técnica do CREAS, também percebeu uma maior integração das adolescentes, que a cada encontro apresentavam maior confiança e liberdade em dialogar sobre temas mais complexos, alguns tabus, como por exemplo: violência sexual e assédio. 
Ao mesmo tempo, foi perceptível que elas desenvolveram maior auto confiança, em expressar o seu ponto de vista, e também de realizar análises críticas sobre os contextos vivenciados no cotidiano.

Outro ponto positivo, visualizado pela coordenadora da Escola/Casa Familiar Rural, é que os adolescentes do gênero masculino, também reivindicavam o desenvolvimento e participação em um grupo só deles. Sendo assim, a avaliação sobre o projeto foi positiva, o que nos leva a refletir sobre a possibilidade de expansão.

\section{Considerações finais}

O Projeto Rizoma, foi realizado em um município de pequeno porte I, no ano de 2019, e foi idealizado como uma forma de resposta a uma demanda intersetorial entre as Políticas de Educação e Assistência Social. Este projeto contou com nove encontros no total, que foram desenvolvidos a partir de dinâmicas de grupo. O público alvo do projeto, eram adolescentes do gênero feminino, que estavam matriculadas na Escola/Casa Familiar Rural.

Este relato de experiência, visa dar visibilidade a uma forma de trabalho intersetorial, que cumpriu o objetivo de resgatar a autoestima e desnaturalizar as diversas expressões da violência de gênero.

No primeiro item do trabalho, denominado como "Plantando uma Semente: O surgimento do projeto" buscamos apresentar as plataformas do planejamento das atividades, ao dar ênfase sobre a ligação que procuramos construir entre a dinâmica rural (esfera microssocietária/espaço privado) e o movimento feminista (esfera macrossocietária/espaço público).

No segundo item, denominado como "Germinação: Desenvolvimento dos Encontros", buscamos detalhar a metodologia e o objetivo empregado em cada um, dos nove encontros realizados com o grupo de adolescentes. 
No terceiro item, intitulado como "Novas Sementes: Os resultados parciais do Projeto" buscamos apresentar alguns impactos que foram observados na (e pela) atividades desenvolvidas através do projeto. Essa avaliação foi realizada tanto pela equipe que desenvolveu o Projeto, mas também, pela equipe pedagógica da Escola/Casa Familiar Rural.

A partir dessa breve descrição das atividades, torna-se possível inferir que o projeto teve um impacto positivo, e que cumpriu com a sua finalidade de trabalho, ao contribuir para o fortalecimento da união entre as adolescentes, e para o desenvolvimento do sentimento de confiança e de pertencimento ao grupo, que passaram a expressar melhor os seus sentimentos e desnaturalizar os estereótipos de gênero presentes no cotidiano, logo, foi perceptível uma significativa diminuição dos conflitos interpessoais entre as adolescentes, e consequentemente dos encaminhamentos para a Unidade Básica de Saúde.

\section{Referências}

Acorda, Raimundo... Acorda!. Direção de Alfredo Alves, Rio de Janeiro, 1990: CETA-IBASE, Iser vídeo. 1 vídeo (22 min). Publicado pelo canal TVPUC. Disponível em:

https:/ / www.bing.com/videos/search?q=acorda+raimundo\&docid $=608023792775663384 \& \mathrm{mid}=1$ F772D74A4AFFD86E6651F772D74A4A FFD86E665\&view=detail\&FORM=VIRE. Acesso em: 30 ago. 2020.

BRAGHIROLLI, Elaine Maria et al. Psicologia Geral. Rio de Janeiro: Vozes, 2014.

BRASIL. Ministério do Desenvolvimento Social. Tipificação dos Serviços Socioassistenciais. Disponível em:

http:/ / aplicacoes.mds.gov.br/snas/documentos/livro\%20Tipificaca $\% 20$ Nacional $\% 20$

\%2020.05.14\%20\%28ultimas \%20atualizacoes\%29.pdf. Acesso em: 30 ago. 2020. 
COSTA, Suely Gomes. Onda, rizoma e "sororidade" como metáforas: representações de mulheres e dos feminismos (Paris, Rio de Janeiro: Anos 70/80 do século XX). INTERthesis, Florianópolis, v. 06, n. 2, jun./dez. 2009.

GARCIA, Juliana. Equilibrando prós e contras da vida. Personare: Do autoconhecimento ao bem-viver. Disponível em: https:/ / www.personare.com.br/equilibrando-pros-e-contras-davida-m2154. Acesso em: 30 ago. 2020.

JUNIOR, José Carlos do Amaral; ALVES, Ana Elizabeth Santos. O olhar sobre a família na Economia Doméstica: análise da relação na efetivação de uma Política de Estado. Disponível em: https:/ / www.congressoservicosocialuel.com.br/trabalhos2019/asse ts/4604-229385-35478-2019-03-26-o-olhar-sobre-a-fami--769-lia.pdf. Acesso em: 30 ago. 2020.

PEDRO, Joana Maria. Traduzindo o debate: o uso da categoria gênero na pesquisa histórica. História, São Paulo, v. 24, n. 1, p. 77-98, 2005.

VANZELA, Alana Morais; SILVA, Elizete Conceição. O papel social de gênero e o patriarcado: dominação e função. Disponível em: < http://www.uel.br/pos/mestradoservicosocial/congresso/anais/T rabalhos/eixo5/oral/30_o_papel_de_genero....pdf>. Acesso em 30 agosto 2020 . 